\title{
Financial Deepening in Mexico
}

\author{
Alexander Herman \\ U.S. Department of Treasury, Office of International Affairs \\ alexander.herman@treasury.gov
}

Alexander Klemm ${ }^{1}$

International Monetary Fund

aklemm@imf.org

\begin{abstract}
International comparisons reveal that - even controlling for a host of explanatory factors credit depth is exceptionally low in Mexico. Using panel data methods linking credit growth and fundamentals, this paper estimates a long-term gap between actual and expected credit of about 40 percent of GDP. Possible explanations include the history of banking crises, the large informal sector and an inefficient legal system. Using a disequilibrium regression approach, this paper also finds that supply factors are particularly important as determinants of credit in Mexico. Recent financial reforms address many of the supply constraints, but their success will depend on implementation. The main challenge going forward will be to support financial deepening, while limiting risks to financial stability.
\end{abstract}

JEL Classification: G18; G21; O16.

Keywords: Mexico; credit gap; credit growth; financial development.

\section{INTRODUCTION}

The Mexican economy has been marked by low growth by emerging market standards over the last decades. Following the improvements in macroeconomic frameworks and the recent structural reforms, it is important to ensure that there are no other factors holding back the expected improvement in growth rates. One of the potentially important conditions for economic growth is the availability of financial intermediation, as recent studies (e.g., Sahay and others (2015) and papers quoted therein) have shown a positive growth impact from financial development. The economic benefits of deepening financial integration need to be weighed against the risks to financial stability. Excessive credit growth can lead to financial risks and has been shown to be one of the most robust predictors of banking and currency crises (the other predictor being real appreciation, see Gourinchas and Obstfeld (2012)). This is particularly important in an environment of rising interest rates. This would immediately affect the affordability of variable interest rate loans, but ultimately also the cost of rolling over fixed-term debt, and it could entail

Corresponding author. Address: International Monetary Fund, $70019^{\text {th }}$ street NW, Washington, DC 20431. Phone: +1 202-623-5339. 
risks for financial institutions with maturity mismatches. The question of whether credit and its growth are too low or too high is therefore of great policy relevance.

This paper aims to analyze the depth of financial intermediation in Mexico. The starting hypothesis is that credit depth is exceptionally low. This hypothesis is tested both descriptively, by comparing to other countries, and more formally, in regressions that control potential explanatory factors. In assessing such credit gap, the main interest is in the structural long-term gap, but empirically it can be difficult to disentangle this from the cyclical credit gap, which we also briefly look into. Having confirmed the presence of a structural credit gap, the paper then uses empirical methods to ascertain whether credit growth is mostly demand or supply driven in Mexico. On this we have an open mind, as one could think of both demand and supply factors that hold down credit growth in Mexico, notably the history of financial crises is likely have affected both borrowers and lenders. The contribution of this paper is to show that credit depth in Mexico is indeed very low, even controlling for typical explanatory factors. We show that this is mostly supply driven, and discuss the expected impact of recent financial reforms.

The paper is structured as follows: Section 2 provides a descriptive analysis of credit in Mexico, both in terms of its components and its recipients, documenting the low level of credit depth by international comparison, and the role of the private sector. Section 3 assesses more formally the size of the credit gap in Mexico, using both a short-term approach, looking at deviations from trend credit growth, and a long-term approach, comparing credit depth in Mexico and other economies, controlling for macroeconomic and structural fundamentals between 1990 and 2014. Section 4 discusses possible reasons for the low level of financial intermediation, including through a disequilibrium regression analysis, exploiting higher frequency data between January 2007 and February 2015 to see whether credit growth is supply or demand driven. Section 5 discusses recent policy developments and the likely time frame of and obstacles to financial deepening. Section 6 concludes.

\section{DESCRIPTIVE ANALYSIS OF CREDIT IN MEXICO}

Credit depth is very low in Mexico, not only in comparison to advanced economies, but also emerging markets. Bank credit is about a quarter of the level observed in other emerging markets, including Brazil, and it is just $1 / 6^{\text {th }}$ of advanced economy average (Figure 1 ). While this paper focuses on bank credit, even total credit is comparatively low, so including other sources of credit should not change this broad finding. One caveat is that informal credit may play an important role, given the large size of Mexico's informal sector.

\section{Figure 1.}

Credit to the Nonfinancial Private Sector, 2015

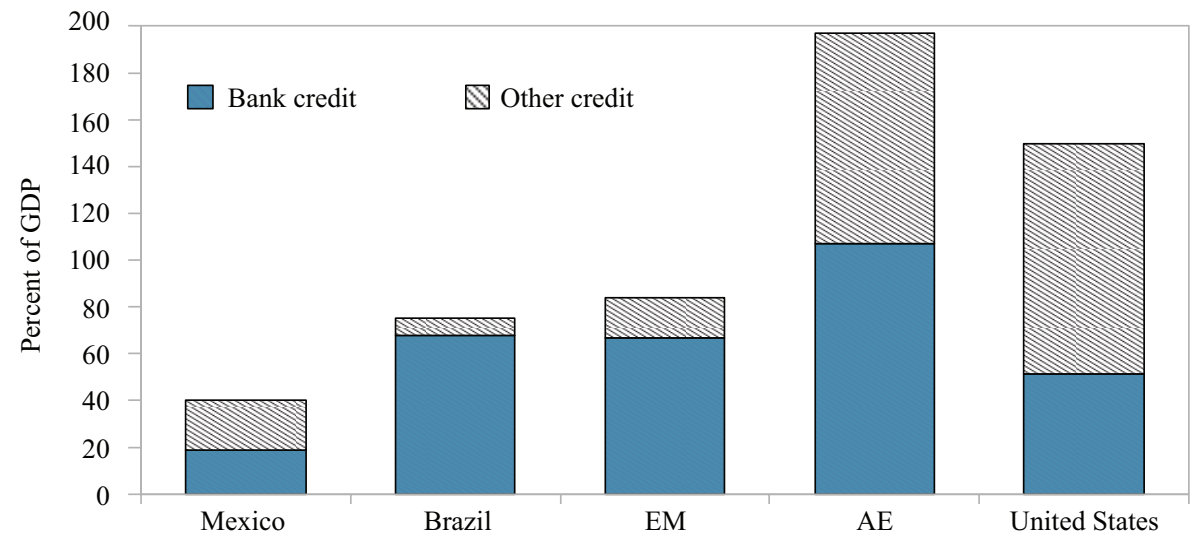

Sources: BIS and Banxico. 
The low degree of financial intermediation has been a feature of the Mexican economy for the last two decades and - apart from a short-lived boom in the early nineties - many years before. In particular, credit to firms has been low, which is worrying, as empirically this part of credit is particularly important for growth (Angeles, 2015). Given prudent macroeconomic policies, this is not caused by financial repression. Indeed, bank credit to the public sector is also quite low and while there may be some crowding out of other lending, it is unlikely to be a sufficient explanation (Figure 2).

Figure 2.

Recipients of Banking System Credit

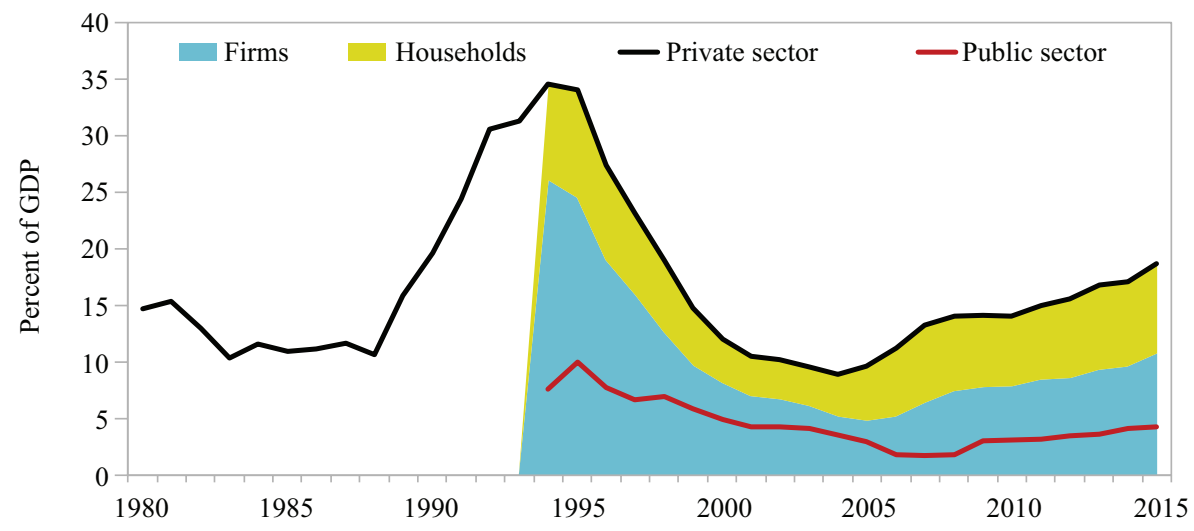

Sources: BIS and Banxico.

Summary measures of overall financial sector development are negatively affected by the low level of credit depth (Figure 3). Mexico has fallen behind the LA5 (the other financially integrated economies in Latin America: Brazil, Chile, Colombia, Peru, and Uruguay), although still remains above the overall LAC (Latin America and Caribbean) average. An analysis of the components of the financial development index ${ }^{2}$ reveals that Mexico's market development is quite strong, but the institutions lag behind the LA5. Among the institutional components, access and depth are weak, with the low value for depth driven by the low credit figures, and also low deposits and a small stock of insurance and mutual fund assets. The low value for access is the result of a comparatively small network of branches, and to a lesser extent a comparative scarcity of ATMs.

Figure 3.

Financial Development in Mexico and Latin America

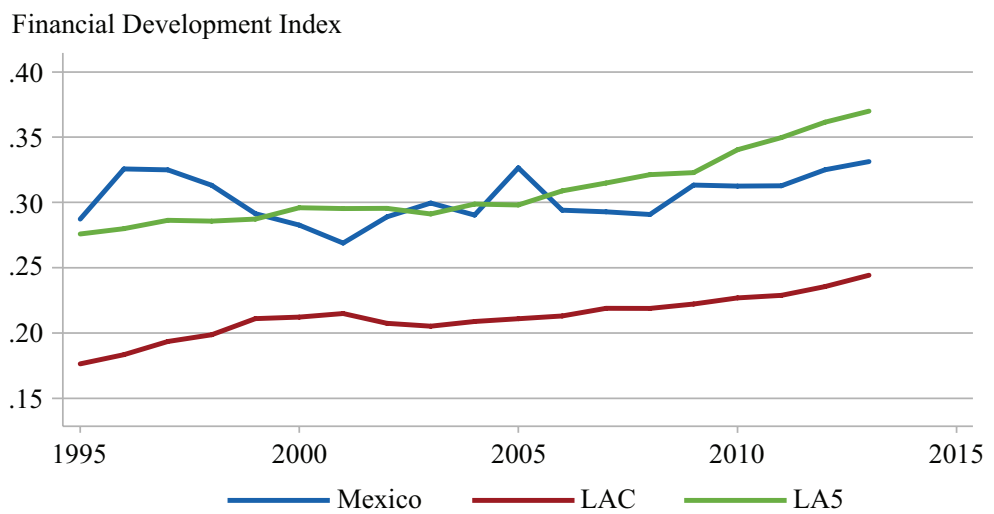

Note: $\mathrm{LAC}=$ Average of Latin American and Caribbean economies other than Mexico; LA5 = Brazil, Chile, Colombia, Peru, and Uruguay. Sources: Heng and others (2015) and authors' calculations.

2 The financial development index was developed in Sahay and others (2015). It covers markets and institutions, and looks in each of them for variables that proxy for access, depth, and efficiency. The data used here are from the October 2015 Western Hemisphere REO (Heng and others, 2015) which calculates this index for Latin American economies. 
Financial deepening does not necessarily imply financial inclusion, and access to credit remains indeed difficult for some individuals and businesses. According to the World Bank Financial Inclusion Database, 51 percent of adults borrowed some money in 2014, but only 10 percent (up from 8 percent in 2011) used a formal financial institution. According to the 2010 World Bank enterprise survey, access to credit by small and medium-sized firms is low by international standards: only 27 percent of small firms had access to credit, compared to 38 percent on average in Latin America and 29 percent worldwide. Among medium-sized firms, 27 percent had access, compared to 56 percent on average in Latin America, and 43 percent worldwide. CNBV data show that the amount of credit has been growing for most categories. However, the number of businesses obtaining loans has stagnated in the case of medium-sized firms and recently even fallen in the case of microenterprises (Figure 4). According to the World Bank's Doing Business Indicators, however, Mexico fares relatively well in terms of ease of getting credit, with a rank of 12, and a distance to frontier of 20 percentage points (down from 25 percentage points in 2014) in 2015. The subcomponent of the strength of legal rights was however a weak point (at 8 out of 12 points).

Figure 4.

Mexico: Bank Loans to Enterprises
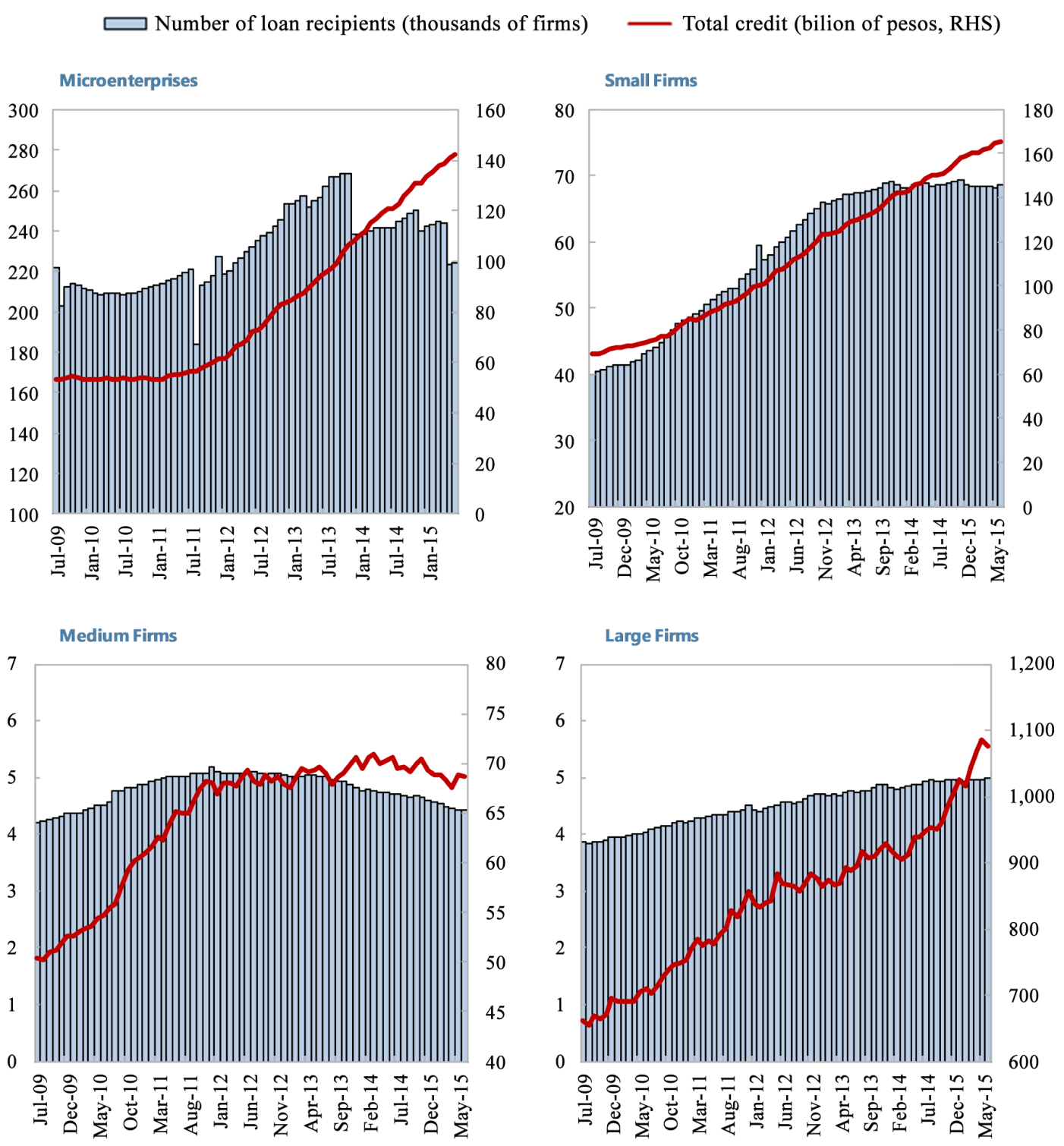

Source: CNBV. 


\section{CREDIT DEPTH IN MEXICO}

\subsection{Credit cycles}

Before tackling the estimation of long-term credit gaps, we briefly review estimates of the cyclical credit gap, which is small in Mexico (Figure 5). This means that credit is currently growing close to its trend rate. However, if there is a structural change in trend credit growth, then estimates based on an HP-filter are hard to interpret. Credit cycles also appear to lag output cycles, a finding which has also been confirmed in a dedicated empirical study (Banco de Mexico (2010), Box 3).

\section{Figure 5.}

Credit and Output Gaps

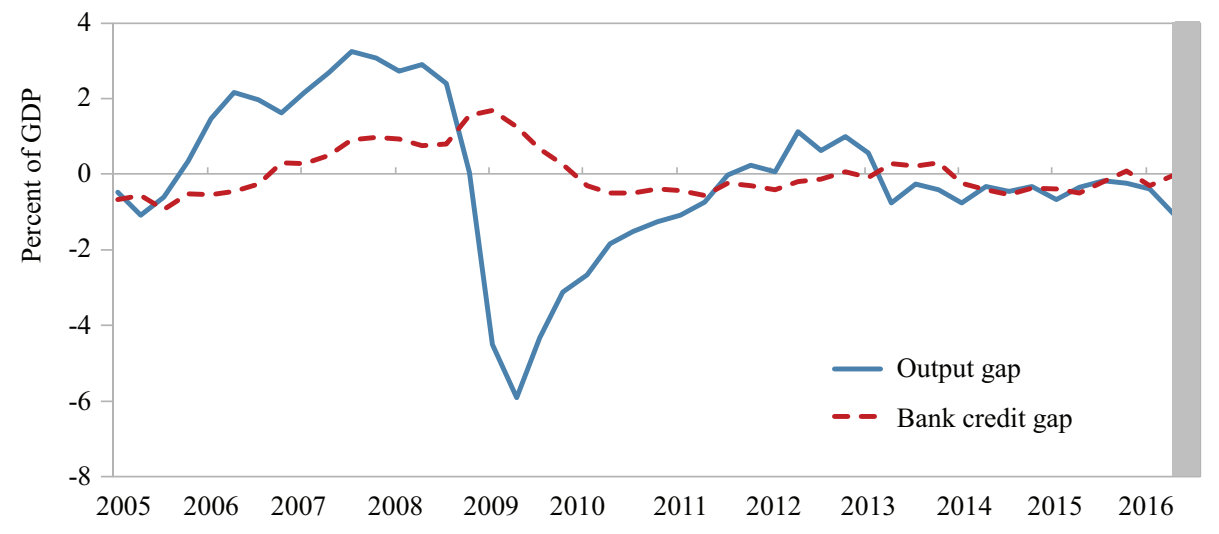

Sources: National authorities; and authors' calculations.

Empirical evidence suggests that credit and real cycles are synchronized, but not very strongly. Indeed, credit cycles have been shorter and more volatile on average ${ }^{3}$ between 1980 and 2014 (Table 1).

Table 1.

Mexico: Synchronization of Credit and Real Cycles

\begin{tabular}{lcccc}
\hline \hline & $\begin{array}{c}\text { Number of cycles } \\
(1980-2014)\end{array}$ & $\begin{array}{c}\text { Average cycle duration } \\
\text { (in years) }\end{array}$ & Amplitude & $\begin{array}{c}\text { Synchronization Ratio } \\
\text { with GDP }\end{array}$ \\
\hline GDP & 8 & 4.4 & 0.3 & 1.00 \\
Total credit & 12 & 2.9 & 0.8 & 0.54 \\
Commercial bank credit & 10 & 3.5 & 1.0 & 0.56 \\
Other credit & 13 & 2.7 & 0.9 & 0.49 \\
\hline \hline
\end{tabular}

Note: Amplitude is defined as the standard deviation divided by the mean of a series. Synchronization ratio is the ratio of number of observations where GDP and credit are in the same phase divided by total observations.

Source: Authors' calculations.

Cyclical analysis cannot reveal structural credit gaps. While there does not appear to be a shortterm credit gap in Mexico, international comparative data are needed to assess the structural level of financial intermediation. Moreover, if Mexico is in a process of increasing credit depth, then estimated trend growth may be affected by a structural increase lasting many years.

3 The findings on the length of financial cycle are broadly comparable to results from other countries, see Claessens (2011). 


\subsection{Credit depth in international comparison}

Regressions linking credit growth and fundamentals using international panel data allow the estimation of expected credit levels in Mexico. Specifically, we estimate a random-effects regression linking credit depth to fundamentals using annual data from advanced and emerging markets between 1990 and 2014. The specification follows closely Cottarelli and others (2005):

$$
\frac{\mathrm{BCPS}}{\mathrm{GDP}}=X \beta+u_{i}+\varepsilon_{i t}
$$

where BCPS stands for bank credit to the private sector, $u_{i}$ is a random effect and $\varepsilon_{i t}$ an error term. $X$ contains explanatory variables, which are: public debt as a share of GDP, logged per capita GDP, inflation, ${ }^{4}$ capital account openness (Chinn and Ito (2006), updated data through 2014), bank regulation indicators, ${ }^{5}$ a dummy for German legal origin (as proxy for greater creditor protection), and a time trend.

This regression is estimated both on a panel of advanced and emerging markets and a panel of only emerging markets, in both cases excluding Mexico. ${ }^{6}$ The regression results are broadly in line with expectations (Table 2). Regressions (1) and (2) show the basic results for the full and emerging market samples. In both samples, an increase in public debt is associated with less credit to the private sector, suggesting some crowding out. Rising incomes are associated with greater credit depth, although the effect is only statistically significant in emerging market sample. Inflation is mostly insignificant. Great capital account openness is associated with deeper credit. Structural variables on banking regulation and the legal background turn out insignificant. In the full sample, there is also a positive time trend, revealing the worldwide increase of credit over the last decades. Given Mexico's low levels of credit depth relative to other economies, we expect the model to suggest a higher level of bank credit to GDP in Mexico than actually observed.

Having estimated the coefficients, they are then used to predict the expected level of credit depth in Mexico, given its fundamentals. Based on estimates from the full sample, including advanced economies, credit would be expected to reach almost 100 percent of GDP given Mexican fundamentals (Figure 6). Based on estimates from the sample of emerging markets only, bank credit would be expected to reach 60 percent of GDP. This implies a structural longterm bank credit gap between 40 and 80 percent of GDP, given the current credit levels of around 20 percent of GDP.

To allow for the impact of bank crises, a variable containing the number of years the banking system was in crisis (using data from Laeven and Valencia (2012)) in each country is added (Regression (3) in Table 2). With this approach, Mexican credit depth appears to be in line with expectations during the crisis years. After the year 2000, however, when macroeconomic policy stabilized, credit would have been expected to be much higher. In recent years, the resulting gap is the virtually the same as in the specification without a crisis variable. As these are estimates of the long-term gap, it does not mean that following the crisis credit would be expected to jump up, but rather that the expected level that should be reached over the medium term is much higher in the absence of a crisis.

\footnotetext{
4 Just like Cottarelli and others (2005), we follow Kahn and others (2001) and model inflation using a non-linear threshold specification, by adding an inflation variable that is defined as (1/inflation - 1/threshold), which is then interacted with the threshold of 4 percent.

5 The two variables used are an index of entry into banking requirements from and the quality of bank accounting, both at the level of 1999. As the indexes do not change much over time adding value for later surveys (available for 2003, 2007, and 2011) did not affect results. Data are from the World Bank: Bank Regulation and Supervision, updated 2012.

6 The emerging market sample includes, apart from Mexico: Brazil, China, Hungary, India, Indonesia, Malaysia, Poland, Russia, Saudi Arabia, South Africa, Thailand, and Turkey. The full sample, additionally includes: Australia, Austria, Belgium, Canada, the Czech Republic, Denmark, Finland, France, Germany, Greece, Ireland, Italy, Japan, Korea, Netherlands, Portugal, Singapore, Spain, Sweden, Switzerland, the United Kingdom, and the United States.
} 
Table 2.

Regressions of Bank Credit on Fundamentals

(1)

(2)

(3)

Full sample

EM sample

\begin{tabular}{lccc}
\hline Public debt/GDP & $-0.15^{*}$ & $-0.14^{* *}$ & $-0.55^{* *}$ \\
& $(0.08)$ & $(0.06)$ & $(0.27)$ \\
ln(GDP/population) & -0.20 & $20.11^{* * *}$ & 8.32 \\
& $(7.27)$ & $(7.34)$ & $(12.05)$ \\
Inflation variable, inflation $<=4$ percent & $0.11^{* * *}$ & 0.64 & 5.69 \\
& $(0.02)$ & $(0.78)$ & $(4.95)$ \\
Inflation variable, inflation $>4$ percent & -48.09 & 5.64 & $428.42^{* * *}$ \\
& $(37.75)$ & $(33.37)$ & $(104.84)$ \\
Capital account openness & $5.67^{* *}$ & $3.70^{* *}$ & -4.22 \\
& $(2.61)$ & $(1.82)$ & $(3.22)$ \\
Entry into banking requirements & 0.96 & -28.58 & -0.10 \\
& $(3.39)$ & $(26.78)$ & $(19.23)$ \\
Bank accounting quality & 11.95 & 8.88 & 5.43 \\
& $(9.62)$ & $(27.35)$ & $-13.90)$ \\
German legal origin dummy & 12.68 & -15.92 & $(21.21)$ \\
Bank crisis dummy & $(15.03)$ & $(27.29)$ & -2.75 \\
& & & $(3.65)$ \\
Trend & & & $-1.86^{*}$ \\
Constant & $1.71^{* * *}$ & 0.10 & $(0.96)$ \\
& $(0.41)$ & $(0.51)$ & 47.71 \\
Observations & 8.64 & 54.91 & $(123.32)$ \\
Number of countries & $(56.68)$ & $(135.75)$ & 193 \\
R-squared, overall & 784 & 268 & 10 \\
\hline \hline
\end{tabular}

Random effect estimation on all countries other than Mexico. Robust standard errors in parentheses.

*** $\quad \mathrm{p}<0.01,{ }^{* *} \quad \mathrm{p}<0.05,{ }^{*} \quad \mathrm{p}<0.1$.

Source: Authors' calculations.

Figure 6.

Bank Credit to the Private Sector

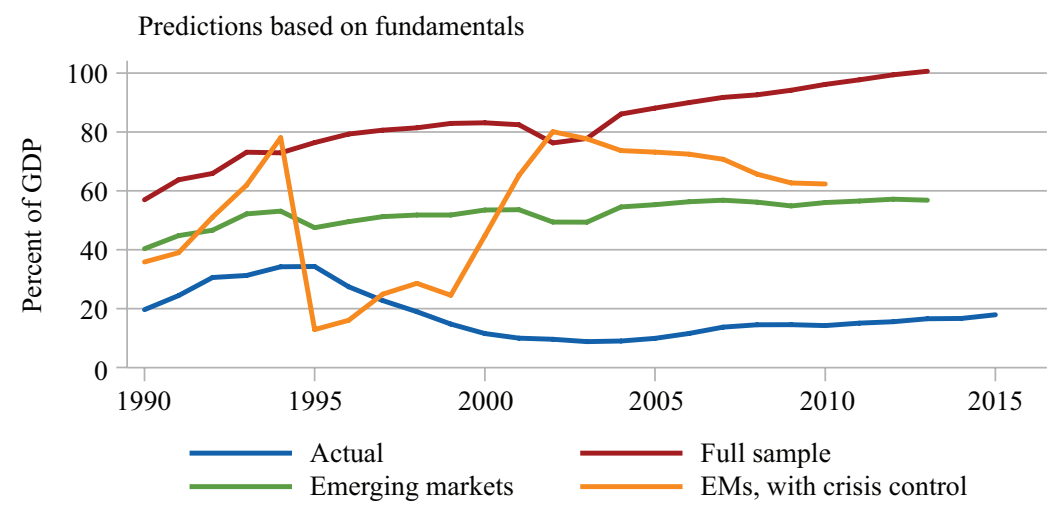

Source: Authors' calculations. 


\section{REASONS FOR THE LOW LEVEL OF FINANCIAL INTERMEDIATION}

\subsection{History of banking crises}

The Mexican banking sector has had a tumultuous history, with two major banking crises since 1980. During the debt crisis of 1982, Mexican banks were nationalized and reduced in numbers through mergers. They faced tight regulations, such as interest rate caps and credit allocation regulations, which limited possibilities for credit growth. In the early 1990s the sector was liberalized, banks were privatized again, and new banks also entered the market. Credit supply boomed, but lending standards were low, possibly because of lack of experience after the years of state-owned banking. There were also weaknesses in financial supervision, for example banks circumvented the not open foreign currency exposure limit of 15 percent of capital by using derivatives. The currency crisis of 1994 then had a greater than expected impact on banks, both through international funding difficulties, and because of rising NPLs, resulting from the economic crisis, and specifically from the widespread use of variable rate mortgages, which were affected by the interest rate rises. A major rescue program, partly financed by the IMF and the U.S., was put in place addressing (i) the short-term funding needs of banks that lost access to international markets and (ii) recapitalization needs, both through capital injections via convertible debt and the purchase of NPLs above market value. For some banks these programs were insufficient and the government needed to intervene and take them over. Additionally, various programs were set up to support debtors, especially for mortgages. ${ }^{7}$ Overall, estimates of the cost of financial sector support are about 15 percent of GDP (see, for example, McQuerry (1999)).

The history of banking crisis is likely to have had lasting effects. Trust in financial institutions was eroded, both for savers who lost deposits in the crisis of the 1980s and for borrowers, who faced difficulties due to rising interest rates in the 1990s. Moreover, banking know-how was lost, because following the nationalization of banks, a tightly regulated system required very different skills from commercial banking and offered lower rewards. While these effects are likely to have largely faded, the legacy of a years of slow credit and deposit growth still affects today's stocks, even though growth is now at a healthy pace.

\subsection{Structure of the banking sector}

Lack of competition in the banking sector may play a role, but does not seem to be a major impediment. Claessens and Laeven (2004) show that already between 1994 and 2001, banking competition as measured by the $\mathrm{H}$-statistic ${ }^{8}$ was relatively high in Mexico compared to other economies. We also estimate an updated $\mathrm{H}$-statistic, which shows a slow, improvement in competition over time (Figure 7 ). The Herfindahl concentration index ${ }^{9}$ stands at 0.13 , indicating that the commercial banking sector is moderately concentrated. Recent developments in lending and deposit rates also suggest that competition may be intensifying as spreads are coming down, particularly for micro enterprises (Figure 8).

\footnotetext{
This paragraph draws heavily on Graf (1999), which contains further details on the post 1994 banking crisis.

8 The H-statistic is a measure of industry competitiveness, where one equals perfect competition, and is calculated by estimating the change in a bank's marginal costs given its equilibrium total revenues.

9 This is defined as $\sum_{i=1}^{n} a_{i}^{2}$, where $a_{i}$ corresponds to a bank's market shares based on total gross credit provision.
} 
Figure 7.

Competition in the Banking Sector

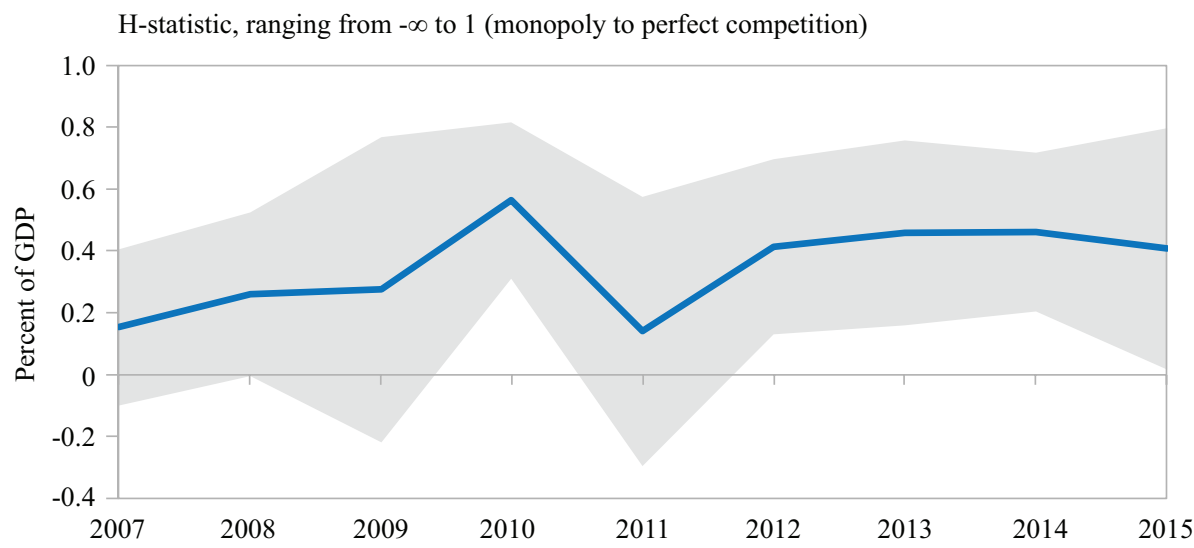

Source: Authors' calculations.

Figure 8.

Marginal lending rates to enterprises

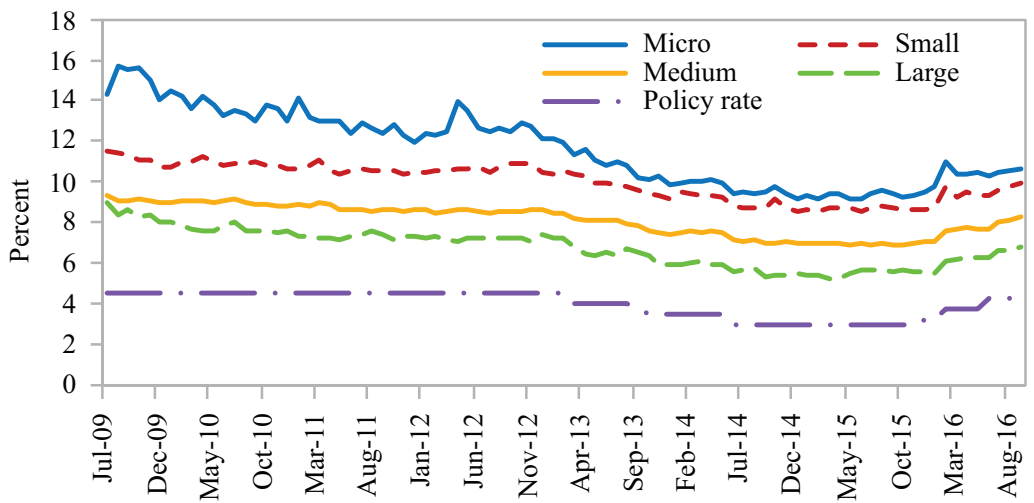

Source: CNBV and Bank of Mexico.

Regressions using a disequilibrium approach allow for distinguishing between supply and demand factors in determining credit growth. Following Everaert and others $(2015)^{10}$ we use a disequilibrium approach to estimate credit demand and supply separately, using monthly data between January 2007 and February 2015. Thus, actual credit is estimated to be the minimum of both:

$$
\begin{aligned}
& C^{D}=\beta_{1}{ }^{\prime} X_{1}+\varepsilon^{D} \\
& C^{S}=\beta_{2}{ }^{\prime} X 2+\varepsilon^{S} \\
& C=\min \left(C^{D}, C^{S}\right)
\end{aligned}
$$

where $C$ is new credit to firms measured in real monthly terms, superscripts $S$ and $D$ indicate supply and demand, and $X_{1}$ and $X_{2}$ are two sets of explanatory variables. Both include the real lending rate as the price of credit. Moreover, demand equation contains the NPL ratio as a measure of debt overhang, consumer confidence as a measure of economic conditions, and the growth of the stock market as a measure of alternative funding sources. The supply equation includes also

10 Based on a methodology originally proposed by Laffont and Garcia (1977). 
the NPL ratio as measure of debt overhang, the deposit rate as a measure of funding costs, and banking system capital as a share of the minimum capital requirement as a measure of capacity to lend. This set of related equations is estimated using a maximum likelihood method developed by Maddala and Nelson (1974). Here, we take an agnostic approach in hypothesizing whether credit was supply or demand driven; since a number of factors may drive both demand and supply, as laid out in Everaert and others (2015), presupposing the role of demand and supply is difficult.

An analysis of supply and demand for credit suggests that in recent years, credit was mostly supply driven (Figure 9). Since 2008, credit supply has been insufficient to meet demand by about MXN (of 2010) 300 billion in recent months. While the estimated figures for the gap between demand and supply are quite sensitive to the explanatory variables used, the general finding of supply-driven credit flows remains robust over many possible choices.

\section{Figure 9.}

Predicted Credit Demand and Supply

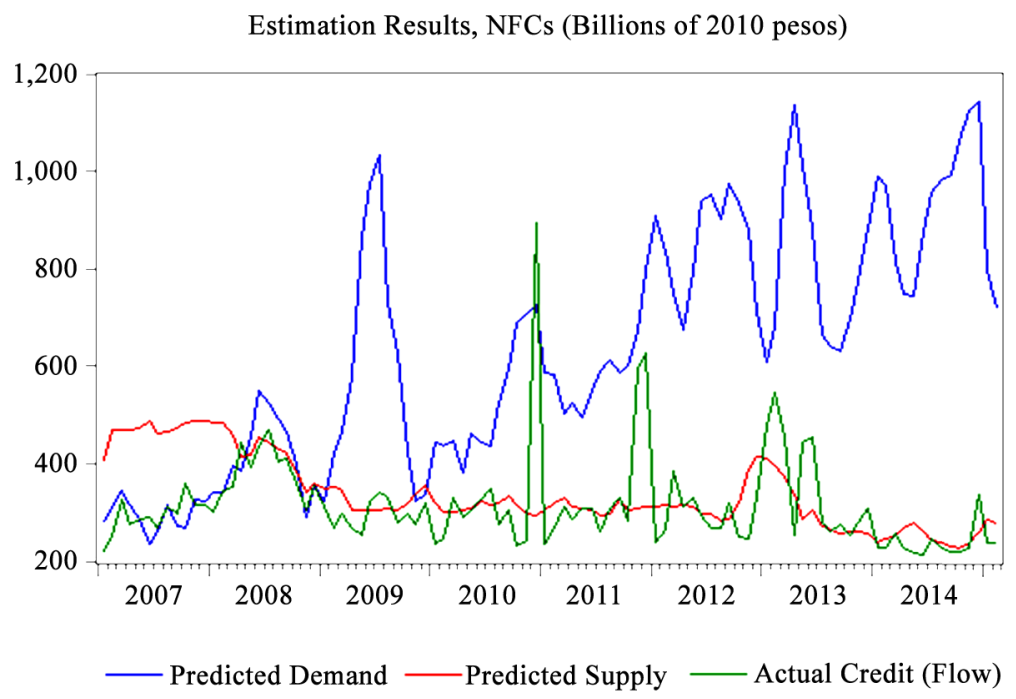

Source: Authors' estimates.

To approach the behavior of banks from yet another angle, we also run regressions relating bank credit to deposits reveal the long-run relationship between both. Similar to Hansen and Sulla (2013), the long-run relationship between bank credit and deposits is estimated using a pooled mean regression:

$$
\frac{\mathrm{BCPS}}{\mathrm{GDP}}=\alpha+\beta \frac{\text { Deposits }}{\mathrm{GDP}}+u_{i}+\varepsilon_{i t}
$$

As in equation (1), the coefficient was estimated using international panel data on countries other than Mexico. ${ }^{11}$ Then, predicted bank credit ratios are estimated using Mexico's deposit ratio. Credit and deposits are both low, but the long-run relationship between them is in line with other emerging markets. Given the level of deposits, credit provision is close to what would be expected based on coefficients from other emerging markets (Figure 10). With coefficients estimated on the full sample, however, credit is below expectations, although to a much smaller extent than in the regressions based on fundamentals. These results suggest that the issue is not one of an inability of turning deposits into loans, but rather an overall lack of financial depth, both in terms of loans and deposits.

11 The estimated regression coefficients were: $\hat{\alpha}=12.1(14.4), \hat{\beta}=1.1(0.2)$ for the full sample and $\hat{\alpha}=-19.3(20.3), \hat{\beta}=1.5(0.5)$ for the emerging market sample. 
Figure 10.

Bank Credit to the Private Sector, pooled mean regression

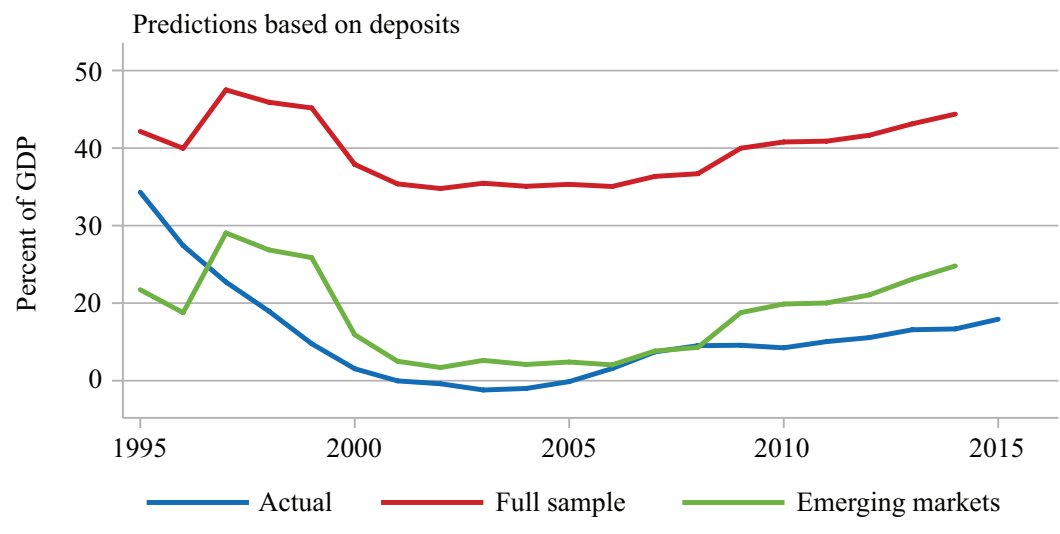

Source: Authors' calculations.

\subsection{Issues beyond the banking sector}

Financial education may still be lacking in some sectors of the economy and some regions of the country. More generally, Campero and Kaiser (2013) have shown that households with greater levels of schooling are more likely to be aware of credit sources (formal and informal) and that regions with greater average schooling levels are marked by greater use of formal credit.

The large informal sector may impede access to financial services. Participants in the informal sector find it harder to document their financial situation, given the absence of tax returns. They may also prefer to deal in cash to avoid leaving traces in the financial system. ${ }^{12}$ Campero and Kaiser (2013) show empirically for Mexico that households employed in the formal sector are 5.7 times more likely to use bank credit than those in the informal sector.

The application of the rule of law remains subject to difficulties. Repossession of collateral, in particular, is difficult and costly to enforce.

\section{CURRENT TRENDS AND POLICIES}

Measures taken in response to the 1994 foreign currency crisis, as well as more recent reforms can be expected to increase trust in the banking system. The Bank of Mexico tightened the regulation on net open foreign currency positions following the 1994 crisis to close the loophole that allowed banks circumventing it by using derivatives or off-balance sheet positions. Financial regulation has been strengthened over the years, and Mexico has been fast in adopting Basel III accord standards, with both the risk-based capital and the liquidity rules assessed as compliant (Basel Committee on Banking Supervision, 2015). The Liquidity Coverage Ratio applies from 2015 and is phased in according to the Basel implementation schedule reaching the final value of 100 percent in 2019. A new deposit insurance institution (IPAB) was set up in 1999. This now insures deposits of up to MXN 2.1 million, ${ }^{13}$ which is clearer and more credible than the previous system, which did not have an explicit limit.

Difficulties in monitoring credit quality and obtaining access to collateral are being addressed. The 2014 financial reform created a new legal instrument to allow for quicker execution of client collateral in case of default. As a result of this and other changes, in the World Bank's (2014) Doing Business data, Mexico's distance to frontier indicator for resolving bankruptcy improved by 6.5 percentage points. More mercantile matters, such as loans involving physical collateral,

12 Nevertheless, indicators of informality are insignificant in the regressions estimating expected credit depth.

13 Legally it is fixed in the inflation-adjusted unit of account (Unidad de Inversion, UDI) at a level of 400,000 UDIs. 
will be shifted to federal courts, but this is not implemented yet. Information sharing between the private credit bureaus is improved and will contain information from the public mortgage lenders (Infonavit and FOVISSSTE) in addition to information from private banks.

Financial education is being strengthened. CONDUSEF, the financial consumer protection agency provides various online tools. A new Financial Entities Bureau will facilitate product comparisons across financial entities. It already allows a broad comparison of banks and lists abusive clauses and bad practices. The move toward cashless salaries and benefits ${ }^{14}$ familiarizes recipients with financial services. A more general education reform aims at improving the quality of education.

Competition in the banking sector is supported by various measures of the 2014 financial reform. These include new provisions that facilitate the portability of bank accounts and mortgages between banks. Moreover, transparency has been improved by obliging banks to publish comparable interest rates.

The Secretary of Finance has been given the mandate to assess compliance of banks with their objective to support and promote productive sectors and domestic economic growth in accordance to best practices and banking guidelines. The first report was prepared during 2016 and contains recommendations. Banks which are assessed as providing insufficient credit will have to prepare action plans to address this.

At current credit growth rates, credit depth is increasing gradually. The current growth rate of around 15 percent exceeds the rate of nominal GDP growth. While rising credit to GDP shares are sometimes considered a warning sign, in the case of Mexico this is welcome after years of weak credit. According to estimates by Arcand and others (2015), increasing the share of bank credit by 1 percentage point of GDP to 19 percent of GDP (as forecast for 2016), would boost growth by 0.03 percentage points. Increasing the ratio of bank credit to GDP to 60 percent, would boost growth rates by 0.8 percentage points. At a credit growth rate of around 15 percent, and assuming nominal growth of 6 percent over the medium term (potential growth of 3 percent and 3 percent inflation), the predicted bank credit ratio of 60 percent of GDP would be reached in about 13 years. If credit growth were to fall, to a still high level of 10 percent, it would take 30 years. Boosting credit growth even further beyond the current rate, however, would also be risky. Sahay and others (2015) shows that financial deepening at a fast pace leads to increased growth volatility and financial instability. Moreover, the amount of feasible credit growth will also depend on the level of bank capital adequacy and other factors, including nonperforming loans, provisioning, the economic cycle, and sentiment.

Despite the overall low level of credit depth, some sectors have seen excessive growth and subsequent problems. Consumer credit - especially credit cards - has seen large growth rates between 2004 and 2007, but standards were low and the quality of credit fell. A rise in nonperforming loans put a stop to the expansion in 2008. In annual terms, credit contracted every month from September 2009 through March 2011. Nonperforming credit card loans rose from 3.1 percent of credit in January 2004 to a peak of 12.6 percent in May 2009.

\section{CONCLUSIONS}

Credit depth has been exceptionally low in Mexico for decades, but credit growth is recovering. The key challenge going forward will be to encourage further credit expansion without jeopardizing financial stability. This will require a continuation of tight regulation, maintaining high credit standards, and avoiding excessively rapid credit growth.

14 See Babatz (2013) for details on this shift. 
Given the history of bank crises, it is paramount to build up a resilient financial sector in which lenders and borrowers have full trust. The strong financial regulation should therefore be maintained and must not be sacrificed in an attempt to boost credit.

Empirical evidence supports our hypothesis that credit depth in Mexico is lower than what fundamentals would suggest, implying a structural long-term bank credit gap, as well as the idea that structural aspects of the banking sector are behind the low degree of financial intermediation. This latter point is suggested both by results showing that credit growth has been supply-driven in recent years, and by the apparent lagging of credit cycles with respect to business cycles.

The financial reforms over the last few years address the weaknesses but must be strongly implemented and further evolutionary changes will be needed. The shifting of more mercantile matters to federal courts, which is essential for improving bankruptcy procedures and collateral recovery, has been delayed and should be urgently implemented. The IPAB needs to be put on a stronger financial footing to strengthen its credibility, as the fund now contains just a very small percentage of the insured deposits. The new mandate that allows the Finance Secretary to scrutinize banks' compliance with their mandates could be risky depending on its implementation. The perception of putting pressure on banks to increase lending could have negative financial stability consequences, although the strong regulatory standards provide protection. The international financial system is undergoing continuous reform, with Basel III still not completely agreed among the Basel Committee members. Mexico will have to follow these developments and ensure that Mexican law evolves in line.

\section{Acknowledgements}

The views expressed in this paper are those of the authors and do not necessarily represent the views of the IMF, its Executive Board, or IMF management; the U.S. Department of Treasury, the United States Government, or their policies. Alexander Herman worked on this paper while employed by the IMF. We are grateful for comments from J. Araujo, S. Basu, P. Cavallino, J. Chow, A. de la Garza, D. Iakova, R. Rennhack, F. Valencia, an anonymous referee, and seminar participants at the Bank of Mexico.

\section{References}

Angeles, Luis (2015) Credit Expansion and the Economy. Applied Economics Letters 22(13), pp. 1064-1072.

Arcand, Jean Louris, Enrico Berkes, and Ugo Panizza (2015) Too Much Finance? Journal of Economic Growth 20, pp. $105-148$.

Babatz, Guillermo (2013) Sustained Effort, Saving Billions: Lessons from the Mexican Government's Shift to Electronic Payments. Better than Cash Alliance, Evidence Paper.

Banco de Mexico (2010) Reporte sobre el Sistema Financiero. Mexico, D.F.

Basel Committee on Banking Supervision (2015) Eighth Progress Report on Adoption of the Basel Regulatory Framework. Bank for International Settlements.

Campero, Alejandra and Karen Kaiser (2013) Access to Credit: Awareness and Use of Formal and Informal Credit Institutions. Banco de Mexico Working Papers 2013-07.

Chinn, Menzie D. and Hiro Ito (2006) What Matters for Financial Development? Capital Controls, Institutions, and Interactions. Journal of Development Economics 81(1), pp. 163-192.

Claessens, Stijn, and Luc Laeven (2004) What Drives Bank Competition? Some International Evidence, Journal of Money, Credit and Banking 36(3), pp. 563-583.

Claessens, Stijn, M. Ayhan Kose, and Marco E. Terrones (2011) Financial Cycles: What ? How? When? IMF Working Paper 11/76.

Cottarelli, Carlo, Giovanni Dell'Ariccia, and Ivanna Vladkova-Hollar (2005) Early Birds, Late Risers, and Sleeping Beauties: Bank Credit Growth to the Private Sector in Central and Eastern Europe and in the Balkans, Journal of Banking and Finance 29, pp. 83-104. 
Everaert, Greetje, Natasha Che, Nan Geng, Bertrand Gruss, Gregorio Impavido, Yinqiu Lu, Christian Saborowski, Jerome Vandenbusche, and Li Zeng (2015) Does Supply or Demand Drive the Capital Cycle? Evidence from Central, Eastern and Southeastern Europe. IMF Working Papers 15/15.

Gourinchas, Pierre-Olivier and Maurice Obstfeld (2012) Stories of the Twentieth Century for the Twenty-First. American Economic Journal: Macroeconomics 4(1), pp. 226-265.

Graf, Pablo (1999) Policy Response to the Banking Crisis in Mexico. In: Bank for International Settlements, Bank Restructuring in Practice, BIS Policy Papers 6, pp. 164-182.

Hansen, Niels Jakob H. and Olga Sulla (2013) Credit Growth in Latin America: Financial Development or Credit Boom. IMF Working Papers 13/106.

Heng, Dyna, Anna Ivanova, Rodrigo Mariscal, Uma Ramakrishnan, and Joyce Cheng Wong (2015) Advancing Financial Development in Latin America and the Caribbean. In: Western Hemisphere Regional Economic Outlook - Adjusting Under Pressure, Chapter 5, pp. 75-87, International Monetary Fund.

Khan, M., A. Senhadji, B. Smith (2001) Inflation and financial depth. IMF Working Papers 01/44.

Laeven, Luc and Fabian Valencia (2012) Systemic Banking Crises Database: An Update. IMF Working Papers $12 / 163$.

Laffont, Jean-Jacques and Rene Garcia (1977) Disequilibrium Econometrics for Business Loans. Econometrica. 45, pp. 1187-1120.

McQuerry, Elizabeth (1999) the Banking Sector Rescue in Mexico. Federal Reserve Bank of Atlanta Economic Review, Third Quarter 1999.

Maddala, Ganggadharrao and Forrest Nelson (1974) Maximum Likelihood Methods for Models of Market Disequilibrium. Econometrica 42(6), pp. 1013-1030.

Sahay, Ratna, Martin Cihak, Papa N'Diaye, Adolfo Barajas, Ran Bi, Diana Ayala, Yuan Gao, Annette Kyobe, Lam Nguyen, Christian Saborowski, Katsiaryna Svirydzenka, and Seyed Reza Yousefi (2015) Rethinking Financial Deepening: Stability and Growth in Emerging Markets. IMF Staff Discussion Note 15/08.

World Bank (2014) Doing Business 2015: Going Beyond Efficiency. Washington, DC: World Bank Group. 